\title{
Epidemiology and Chemical Control of Take-All on Seminal and Adventitious Roots of Wheat
}

\author{
D. J. Bailey, N. Paveley, C. Pillinger, J. Foulkes, J. Spink, and C. A. Gilligan
}

First and sixth authors: Department of Plant Sciences, University of Cambridge, Downing Street, Cambridge, CB2 3EA. U.K.; second author: ADAS, High Mowthorpe, Duggleby, Malton, North Yorkshire YO17 8BP U.K.; third and fourth authors: Division of Agricultural and Environmental Sciences, University of Nottingham, Sutton U.K.; and fifth author: Bonnington Campus, Loughborough, Leicestershire LE12 5RD U.K.; and ADAS Rosemaund, Preston Wynne, Hereford HR1 3PG. U.K.

Current address of D. J. Bailey: INRA-Bordeaux UMR Santé Végétale, BP, 81, 33883 Villenave d'Ornon, France.

Accepted for publication 30 August 2004.

\begin{abstract}
Bailey, D. J., Paveley, N., Pillinger, C., Foulkes, J., Spink, J., and Gilligan, C. A. 2005. Epidemiology and chemical control of take-all on seminal and adventitious roots of wheat. Phytopathology 95:62-68.

Epidemiological modeling is used to examine the effect of silthiofam seed treatment on field epidemics of take-all in winter wheat. A simple compartmental model, including terms for primary infection, secondary infection, root production, and decay of inoculum, was fitted to data describing change in the number of diseased and susceptible roots per plant over thermal time obtained from replicated field trials. This produced a composite curve describing change in the proportion of diseased roots over time that increased monotonically to an initial plateau and then increased exponentially thereafter. The shape of this curve was con-

phases of the epidemic. However, analysis with the model detected a significant reduction in the rate of primary, but not secondary, infection. The potential for silthiofam to affect secondary infection from diseased seminal or adventitious roots was examined in further detail by extending the compartmental model and fitting to change in the number of diseased and susceptible seminal or adventitious roots. Rates of secondary infection from either source of infected roots were not affected. Seed treatment controlled primary infection of seminal roots from particulate inoculum but not secondary infection from either seminal or adventitious roots. The reduction in disease for silthiofam-treated plants observed following the secondary infection phase of the epidemic was not due to long-term activity of the chemical but to the manifestation of disease control early in the epidemic.
\end{abstract} sistent with consecutive phases of primary and secondary infection. The seed treatment reduced the proportion of diseased roots throughout both

Take-all of winter wheat (Triticum aestivum L.) caused by the soilborne fungal plant pathogen Gaeumannomyces graminis (Sacc.) Arx \& D. Olivier var. tritici J. Walker is an economically important root pathogen of wheat crops in the United Kingdom (10). Genetic resistance has not, as yet, proved useful for disease management, and disease control by application of specific biological agents remains unreliable (15). Even the application of recently developed chemical fungicides delivers variable results (14). Cultural strategies, such as time of sowing and crop rotation (4), remain the most reliable methods for reducing disease risk. Yet, in the absence of take-all, some of these husbandry treatments have a negative impact on yield which must be balanced against their usefulness. All of these control methods are applied with little understanding of their effect on the underlying epidemiological mechanisms for the spread of disease. For optimization of disease control, a more rigorous, mechanistic approach is needed. One such approach is to develop an epidemiological protocol to examine the effects of single or combined control strategies on the spread of disease. At the heart of this protocol lies a mathematical model that embodies the main epidemiological features of the take-all system, whereby an epidemic consists of consecutive phases of primary infection and secondary infection (1). Primary infection occurs from particulate inoculum residing in the soil and, because this inoculum decays relatively quickly during the growing season (9), is largely restricted to the

Corresponding author: D. J. Bailey; E-mail address: dbailey@bordeaux.inra.fr

DOI: 10.1094/PHYTO-95-0062

(C) 2005 The American Phytopathological Society
Additional keywords: disease dynamics, disease progress, root growth. seminal roots (1). Secondary infection occurs between diseased and susceptible roots and may affect both the seminal and adventitious root systems.

Linking the control from a particular treatment with phases of primary or secondary infection on seminal and adventitious roots is appealing (7). By identifying the phase of infection for which control is most effective and the benefits afforded by extending the duration of disease control, it would allow a more informed integration of additional strategies to optimize disease control. Distinction between the two root systems is particularly important if the model is to be linked to the impact of take-all on the capture of resources from belowground $(5,12)$ and, ultimately, to yield. This is because, broadly speaking, the seminal roots provide the supply of water and mineral requirements during autumn and winter establishment of the crop, whereas the adventitious roots contribute increasingly to spring and summer growth during later stages of plant development (13). Clearly, effects of disease on resource capture and yield will depend on which roots of the wheat plant become diseased and when. Conversely, to design the most effective control strategy, we would want to know which of the roots are protected and remain healthy, and for how long.

In this article, we fit a mechanistic, epidemiological model, developed previously from a combination of controlled environment and field experimentation (1), to changes in the numbers of diseased and susceptible roots over time, to examine the effect of a chemical seed treatment, silthiofam (3), on disease dynamics. Data were utilized from intensively sampled field trials. Specifically we asked, did silthiofam affect primary infection from soil inoculum, secondary infection from diseased roots, or both? We extended the model to distinguish between and examine differences 
in the infectivity of seminal and adventitious roots. The potential contribution of this approach to an epidemiological protocol for integrated management of soilborne disease is discussed.

\section{MATERIALS AND METHODS}

Primary and secondary infection of total roots. For each plant, change in the number of susceptible, $S$, and diseased, $I$, roots over time, $t$ (where $t=$ degree-days $>4^{\circ} \mathrm{C}$ ), was described by a compartmental model (model 1$)$.

$\begin{array}{ll}\text { Susceptible roots } & \frac{\mathrm{d} S}{\mathrm{~d} t}=b S \frac{(\kappa-N)}{\kappa}-\left(r_{p} X+r_{s} I\right) S \\ \text { Diseased roots } & \frac{\mathrm{d} I}{\mathrm{~d} t}=\left(r_{p} X+r_{s} I\right) S \\ \text { Particulate inoculum } & \frac{\mathrm{d} X}{\mathrm{~d} t}=-r_{d} X\end{array}$

We assume that the production of the total number of roots, $N$, increases logistically in number over time with a rate $b$ to a maximum, $\kappa$, where $N=S+I$. Disease is initiated by primary infection with a rate, $r_{p}$, from particulate inoculum, $X$, that decays exponentially with time at a rate, $r_{d}$. Disease spreads by secondary infection from diseased to susceptible roots with a rate $r_{s}$.

Primary and secondary infection of seminal and adventitious roots. For each plant, change in the number of susceptible seminal, $S_{\text {sem }}$, diseased seminal, $I_{\text {sem }}$, susceptible adventitious, $S_{\text {adv }}$, and diseased adventitious, $I_{\text {adv }}$, roots over time, $t$, was described by the compartmental model (model 2 ).

\begin{tabular}{|c|c|}
\hline $\begin{array}{l}\text { Susceptible } \\
\text { seminal roots }\end{array}$ & $\frac{\mathrm{d} S_{\text {sem }}}{\mathrm{d} t}=b_{\mathrm{sem}}-\left(r_{p} X+r_{\mathrm{s} 1} I_{\text {sem }}+r_{\mathrm{s} 2} I_{a d v}\right)$ \\
\hline Susceptible & ${ }_{a d v} \frac{\left(\kappa_{a d v}-N_{a d v}\right)}{-\left(r_{p} X+r\right.}$ \\
\hline & $\kappa a d v$ \\
\hline $\begin{array}{l}\text { Diseased } \\
\text { seminal roots }\end{array}$ & $\frac{\mathrm{d} I_{\text {sem }}}{\mathrm{d} t}=\left(r_{p} X+r_{\mathrm{s} 1} I_{s e m}+r_{\mathrm{s} 2} I_{\text {adv }}\right) S_{\text {sem }}$ \\
\hline $\begin{array}{l}\text { Diseased } \\
\text { adventitious roots }\end{array}$ & $\frac{\mathrm{d} I_{a d v}}{\mathrm{~d} t}=\left(r_{p} X+r_{s 1} I_{s e m}+r_{s 2} I_{a d v}\right) S_{a d v}$ \\
\hline $\begin{array}{l}\text { Particulate } \\
\text { inoculum }\end{array}$ & $\frac{\mathrm{d} X}{\mathrm{~d} t}=-r_{\mathrm{d}} X$ \\
\hline
\end{tabular}

The number of seminal roots decayed (as a consequence of systematic sampling error due to increasing disease levels) during the course of the epidemic with a rate, $b_{\text {sem }}$. Adventitious roots, $N_{\text {adv }}$, increase logistically in number over time with a rate $b_{\text {adv }}$ to a maximum, $\kappa_{\text {adv }}$, where $N_{\text {adv }}=S_{\text {adv }}+I_{\text {adv }}$. Disease is initiated by primary infection from particulate inoculum, $X$, with a rate, $r_{p}$, that can affect both susceptible seminal and adventitious roots. However, because we assume that particulate inoculum decays exponentially with time at a rate $r_{d}$, primary infection is restricted mostly to the seminal roots. Disease continues to spread by secondary infection from diseased to susceptible roots. We distinguish between secondary infection from diseased seminal roots with a rate $r_{s 1}$ and that from diseased adventitious roots with a rate $r_{s 2}$. The justification for dual transmission rates for secondary infection is that estimates of $r_{s}$ are increasingly dominated by adventitious roots. This means that any long-term reduction in the infectivity of diseased seminal roots may go undetected.

Both models were fitted by least-squares optimization using Facsimile (MCPA Software Ltd., Oxfordshire, UK). Approximate asymmetrical 5 and $95 \%$ confidence intervals are given for parameters estimated by Facsimile by transformation from a lognormal distribution. Time was converted to thermal time (degreedays $>4{ }^{\circ} \mathrm{C}$ ). The rate of inoculum decay, $r_{d}$, was estimated from epidemics in the absence of the silthiofam treatment and held constant when fitting to data for treated plots. This assumes that the rate of inoculum decay is not affected by the seed treatment and allows direct comparison of transmission rates for primary and secondary infection. For 1998-99 epidemics, model 1 was fitted to change in the number of susceptible and diseased roots over time, providing estimates of $b, \kappa, r_{d}, r_{p}$, and $r_{s}$. Model 2 was fitted to change in the number of susceptible and diseased seminal and adventitious roots over time, providing estimates of $b_{\text {sem }}, b_{\text {adv }}$, $\kappa_{\mathrm{adv}}, r_{d}, r_{p}, r_{s 1}$, and $r_{s 2}$. Commonality (i.e., to identify which parameters were not affected by the silthiofam treatment) among transmission parameters for primary and secondary infection was tested on the basis of residual mean squares (6).

Data for a second season (1999-2000) was examined to test repeatability of the effect of silthiofam on take-all. However, for the epidemics in 1999-2000, collection of data did not begin until after the phase of primary infection. This excluded the possibility of rigorous parameter estimation for the full models 1 and 2 by least-squares fitting. Instead, the thermal time for onset of disease and the decay rate of inoculum, $r_{d}$, was assumed to be the same as for 1998-99 epidemics and only the parameters for root dynamics were fitted. The remaining parameters, $r_{p}$ and $r_{s}$ for model 1 or $r_{p}$, $r_{s 1}$, and $r_{s 2}$ for model 2 , then were fitted by exploring a matrix of data over the parameter space $r_{p}=2.0$ to $8.0 \times 10^{-4}$ and $r_{s}, r_{s 1}$, and $r_{s 2}=5.0$ to $50.0 \times 10^{-5}$ to data for untreated crops. By selecting different values for primary $\left(r_{p}\right)$ and secondary, $\left(r_{s}\right.$ for model 1 and $r_{s 1}$ or $r_{s 2}$ for model 2) infection, this enabled us to test the consistency in the results for 1999-2000 with those of 1998-99. It does not, however, provide an independent test based upon full parameter estimation.

Model simulations. To examine the likely effect of silthiofam on take-all epidemics characterized by different levels of secondary infection, we used parameter estimates obtained from fitting model 1 to field data. Disease progress curves were simulated for epidemics with and without silthiofam to generate curves describing change in the percentage reduction of diseased roots over time.

Field experimentation. Experimental treatments and plot management. One experiment each was conducted in 1998-99 and 1999-2000 at ADAS Rosemaund in Herefordshire $\left(52^{\circ} 07.4^{\prime} \mathrm{N}\right.$, $2^{\circ} 38.2^{\prime} \mathrm{W}$ ) on a silty clay loam (Bromyard series) with good drainage. The two treatments were (i) standard seed treatment only (Beret Gold; Syngenta, UK; a.i. 25 g/liter, 2.43\% wt/wt, fludioxonil); and (ii) standard seed treatment + silthiofam (Monsanto, UK) at $25 \mathrm{~g}$ a.i./100 kg of seed in 1998-99 and $50 \mathrm{~g}$ a.i./100 kg of seed in 1999-2000. Treatments were randomized on four replicate blocks of winter wheat cv. Equinox. Beret Gold is a cyanopyrrole fungicide seed treatment and is effective against Tilletia caries (bunt), and root rot and snow mold caused by Fusarium spp. Silthiofam has high activity and specificity against G. graminis var. tritici (3). It is not considered to have systemic properties.

In 1998-99, the previous cropping was winter barley (1997), winter bean (1996), winter wheat (1995), winter oilseed rape (1994), and winter wheat (1993); in 1999/2000, previous cropping was winter wheat (1998), winter wheat (1997), potato (1996), winter wheat (1995), and winter oilseed rape (1994). The sowing dates were 4 October 1998 and 8 October 1999. Seed rate was adjusted by 1,000-grain weight to achieve a target seed rate of $350 \mathrm{~m}^{-2}$.

Prophylactic foliar applications of fungicides were given at growth stage (GS)31, GS39, and GS59 to keep aboveground diseases to very low levels. Nitrogen fertilizer was applied at a rate of 188 to $189 \mathrm{~kg} \mathrm{ha}^{-1}$ as ammonium nitrate prill, with $40 \mathrm{~kg} \mathrm{ha}^{-1}$ in mid-March and the remainder during April and the first week 
in May. Phosphate fertilizer at $64 \mathrm{~kg} \mathrm{ha}^{-1}$ and potassium at $95 \mathrm{~kg}$ $\mathrm{ha}^{-1}$ were applied prior to sowing on 24 September 1998. The 1999-2000 experiment had nonlimiting P and K contents. A full rate of plant growth regulator was applied at GS31 in 1999, and half-rate treatments were applied on 31 March and 6 May in 2000. Pesticides and herbicides were used as necessary to minimize the effects of pests and weeds.

Take-all assessments. Each plot was subdivided into six subplots (dimensions, 2 by $10 \mathrm{~m}$ ), four of which were used for takeall assessments. The sampling subplot system was utilized to take into account the patchy nature of $G$. graminis var. tritici infection. Twenty-five plants were taken from each plot approximately every 14 days in 1998-99 and every 28 days in 1999-2000. Six plants were taken from each of three subplots and seven plants were removed from the remaining subplot. For each plant, assessments were made of (i) number of seminal root axes, (ii) number of primary adventitious root axes, (iii) number of infected seminal roots, and (iv) number of infected adventitious roots.

\section{RESULTS}

Primary and secondary infection of total roots. In 1998-99, in the absence of chemical treatment, the average total number of roots per plant increased sigmoidally over time from 5.7 after 465 degree-days to 33.8 after 2,211 degree-days (Fig. 1A). During the same period, the average number of diseased roots per plant increased from 0.34 to 19.3 while the number of susceptible roots increased from 5.3 to a maximum of 26.8 after 1,311 degree-days, then decreased to 14.4 after 2,211 degree-days (Fig. 1A). Using these curves, little effect of the seed treatment was observed during the early stages of the epidemic but an increasing effect was observed as the epidemic progressed (Fig. 1A). The reduction in numbers of diseased roots caused by the seed treatment was accompanied by a concomitant increase in the number of susceptible roots over time (Fig. 1A). Silthiofam marginally reduced the final total number of roots by an average of 1.9 roots per plant to 31.9 after 2,211 degree-days (Fig. 1A). In contrast, inspection of curves describing changes in the proportion of diseased roots over time highlighted an effect of the treatment early in the epidemic (Fig. 1B).

Model 1 provided a good description of change in total, diseased, and susceptible roots over time (Fig. 1A). No effect of chemical treatment was detected on the rate of root production, $b$, the asymptotic root number, $k$, or the rate of secondary infection, $r_{s}$. However, a significant reduction of $28.8 \%$ in the rate of primary infection, $r_{p}$, was detected (Table 1). The model describes a monotonic increase in the proportion of diseased roots to an initial plateau after 800 degree-days, followed by a second increase in the rate of disease progress (Fig. 1B). The model marginally overestimates the proportion of diseased roots during the early phase of the epidemic in the absence of chemical treatment, yet still captures the protection afforded by the chemical at the time of the initial disease plateau (Fig. 1B).

In 1999-2000, take-all epidemics were characterized by an extended delay prior to the onset of secondary infection (Fig. 1D); however, otherwise, the trends in disease dynamics and the effect of silthiofam were remarkably similar to 1998-99 (Fig. 1C and D). Model 1 was not fitted statistically to the data but was used to
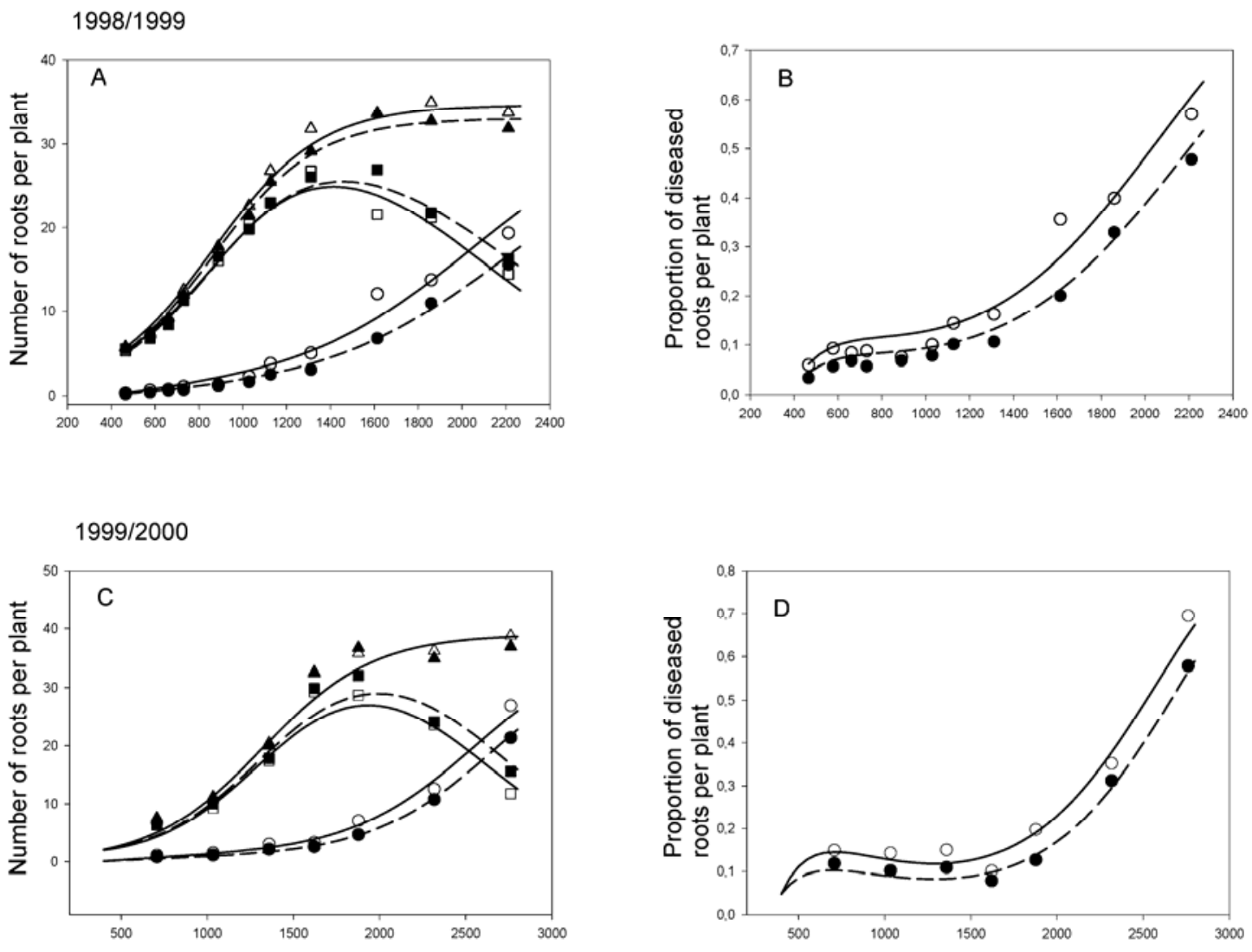

Time (degree-days $>4^{0} \mathrm{C}$ )

Fig. 1. A, Change in number of diseased (circles), susceptible (squares), and total (triangles) roots over time for untreated (open symbols) or treated (closed symbols) wheat plants for season 1998-99. B, Change in the proportion of diseased roots over time for untreated (open circles) and treated (closed circles) wheat plants. C, Change in number of diseased (circles), susceptible (squares), and total (triangles) roots over time for untreated (open symbols) or treated (closed symbols) wheat plants for season 1999-2000. D, Change in the proportion of diseased roots over time for untreated (open circles) and treated (closed circles) wheat plants. Model 1 was used to describe root growth and disease dynamics for untreated (solid lines) and crops treated (broken lines) with silthiofam. 
demonstrate the repeatable effect of silthiofam. Disease dynamics for epidemics with untreated and treated seed could be described accurately using identical values for all parameters of model 1 except the rate of primary infection, $r_{p}$, which was reduced by $27.3 \%$ for treated crops (Table 1).

Primary and secondary infection of seminal and adventitious roots. In 1998-99, in the absence of chemical seed treatment, the average number of seminal roots decreased from 5.6 after 465 degree-days to 4.3 after 2,211 degree-days. The average number of diseased seminal roots increased over time from 0.34 after 465 days degrees to 3.14 after 2,211 degree-days (Fig. 2A), while the average number of susceptible seminal roots decreased from 5.2 after 465 degree-days to 1.2 after 2,211 degree-days. The proportion of diseased roots increased to an initial plateau of 0.17 after 888 degree-days before increasing again to 0.73 after 2,211 degree-days (Fig. 2B). The total number of adventitious roots increased sigmoidally from 0 to 29.5 , the number of diseased adventitious roots increased from 0 to 16.2 , while the number of susceptible adventitious roots increased from 0 to a maximum of 23.8 after 1,310 degree-days, and then decayed to 13.3 after 2,200 degree-days (Fig. 2C). The proportion of diseased adventitious roots increased from 0 to 0.55 after 2,200 degree-days. Addition of silthiofam did not affect change in the total numbers of seminal roots but did reduce disease on both the seminal and adventitious roots systems. For seminal roots, the reduction in disease began during the primary phase of the epidemic and continued through the secondary phase (Fig. 2A and B). No disease was recorded on adventitious roots during the early phase of the epidemic. However, progressively increasing differences in disease levels between untreated and treated plants were detected after 1,000 degree-days (Fig. 2C and D). By the end of the epidemic, the chemical treatment had reduced disease levels by approximately 0.5 seminal roots per plant (Fig. 2A) and five adventitious roots per plant (Fig. 2C).

To identify the process to which disease control may be attributed (i.e., primary or secondary infection) and to identify any reduction in the spread of disease from seminal or adventitious roots of plants treated with silthiofam, model 2 was fitted to changes in the numbers of diseased and susceptible seminal and adventitious roots over time. A $69.2 \%$ reduction in primary infection, $r_{p}$, on seminal roots was detected, but there was no effect of the chemical on secondary infection for either diseased seminal $\left(r_{s 1}\right)$ or diseased adventitious $\left(r_{s 1}\right)$ roots, or on root production (parameters $b_{\text {sem }}, b_{\text {adv }}$, and $k_{\text {adv }}$ ) (Table 2). In 1999-2000, epidemic behavior and control by silthiofam was remarkably similar to 1998-99. Model 2 was not fitted to the data but was used to demonstrate the repeatable effect of silthiofam. By reducing the rate of primary infection, $r_{p}$, for treated crops by $46 \%$, disease dynamics in untreated and treated crops could be described accurately using identical values for all other parameters (Fig. 2E to $\mathrm{H})$ (Table 2).

In 1998-99, silthiofam increased the average combine grain yield at $85 \%$ dry matter from 7,000 to $7,400 \mathrm{~kg} \mathrm{ha}^{-1}(P=0.004)$. In 1999-2000, average yields were lower. Silthiofam increased the average combine grain yield at $85 \%$ dry matter from 4,400 to $5,200 \mathrm{~kg} \mathrm{ha}^{-1}(P=0.012)$.

Simulations of the effect of silthiofam on the efficiency of disease control for epidemics characterized by different levels of secondary infection. Simulations of the change in the reduction in percentage of diseased roots over time by silthiofam for epidemics characterized by different levels of secondary infection suggested a wide range of response (Fig. 3). For all epidemics, the percentage of reduction in diseased roots increased rapidly to $>40 \%$ after 800 degree-days. Although for epidemics with no secondary infection, the reduction in diseased roots increased asymptotically toward $50 \%$ after 2,200 degree-days, for moderate levels of secondary infection, disease control declined to $25 \%$ after 2,200 degree-days and, for high levels of secondary infection, no reduction in diseased roots was predicted after 2,200 degree-days.

\section{DISCUSSION}

In this study, we used an epidemiological analysis to examine the effect of the chemical seed treatment silthiofam on the disease dynamics of take-all. A reduction in the number of diseased roots per plant for treated crops was most evident during the secondary infection phase of the epidemic. However, based on the epidemiological analysis, the mechanism responsible for these differences was associated with the control of primary infection, detected as a reduction in the parameter $r_{p}$, and acting during the initial phase of the epidemic. Moreover, careful inspection of changes in the proportion of diseased roots over time identified an effect of the treatment as soon as the epidemic had begun. These results are broadly consistent with other studies (14), whereby control is limited to primary infection during the early phase of the epi-

TABLE 1. Parameter estimates and approximate 5 and $95 \%$ confidence limits from fitting model 1 to the change in the number of susceptible and diseased wheat roots over time (degree-days $>4^{\circ} \mathrm{C}$ ) for wheat crops grown from seed either untreated or treated with silthiofam ${ }^{\mathrm{a}}$

\begin{tabular}{|c|c|c|c|c|c|c|}
\hline \multirow[b]{2}{*}{ Season, parameter ${ }^{\mathrm{b}}$} & \multicolumn{3}{|c|}{ Untreated } & \multicolumn{3}{|c|}{ Treated } \\
\hline & Mean & $5 \%$ & $95 \%$ & Mean & $5 \%$ & $95 \%$ \\
\hline \multicolumn{7}{|l|}{ 1998-99 } \\
\hline$r_{d}\left(\times 10^{-3}\right)$ & 3.32 (fixed) & & & 3.32 (fixed) & & \\
\hline$k$ & 34.6 & 32.9 & 36.5 & 33.1 & 32.0 & 34.1 \\
\hline$r_{p}\left(\times 10^{-4}\right)$ & 6.99 & 5.11 & 9.55 & 4.98 & 4.04 & 6.13 \\
\hline$r_{s}\left(\times 10^{-5}\right)$ & 7.07 & 6.13 & 8.16 & 7.06 & 6.44 & 7.75 \\
\hline \multicolumn{7}{|l|}{ 1999-2000 } \\
\hline$r_{d}\left(\times 10^{-3}\right)$ & 3.32 & $\ldots$ & $\ldots$ & 3.32 & $\ldots$ & $\ldots$ \\
\hline$b\left(\times 10^{-4}\right)$ & 0.80 & $\ldots$ & $\ldots$ & 0.80 & $\ldots$ & $\ldots$ \\
\hline$k$ & 39.0 & $\ldots$ & $\ldots$ & 39.0 & $\ldots$ & $\ldots$ \\
\hline$r_{p}\left(\times 10^{-4}\right)$ & 11.0 & $\ldots$ & $\ldots$ & 8.00 & $\ldots$ & $\ldots$ \\
\hline$r_{s}\left(\times 10^{-5}\right)$ & 7.00 & $\cdots$ & $\cdots$ & 7.00 & $\cdots$ & $\begin{array}{l}\cdots \\
\cdots\end{array}$ \\
\hline
\end{tabular}

${ }^{a}$ Model 1 also was used to describe epidemics in 1999-2000. Disease dynamics could be described for both epidemics using common values for all parameters except the rate of primary infection, $r_{p}$. Values in bold indicate parameter that are significantly affected by the use of silthiofam.

b Parameters: $r_{d}$ = rate of inoculum decay, measured in (degree-day) ${ }^{-1}$, dimensions $\left(\mathrm{T}^{-1}\right) ; b=$ rate for root production, measured in $(\text { degree-day })^{-1}$, dimensions $\left(\mathrm{T}^{-1}\right)$; $k=$ maximum number of roots, measured in roots, dimensions $\left(\mathrm{L}^{-3}\right) ; r_{p}=$ rate of primary infection, measured in (degree day) ${ }^{-1}$ (inoculum unit $)^{-1}$, dimensions $\left(\mathrm{T}^{-1}\right)$ $\left(\mathrm{L}^{-3}\right) ; r_{s}=$ rate of secondary infection, measured in (degree day) ${ }^{-1}$ (root) $)^{-1}$, dimensions $\left(\mathrm{T}^{-1}\right)\left(\mathrm{L}^{-3}\right)$. Dimensions: inoculum and root densities are properly considered per unit area for a fixed soil depth in which epidemiological significant infections occur.

${ }^{c}$ rss $=$ residual sums squared. 
i) Seminal roots

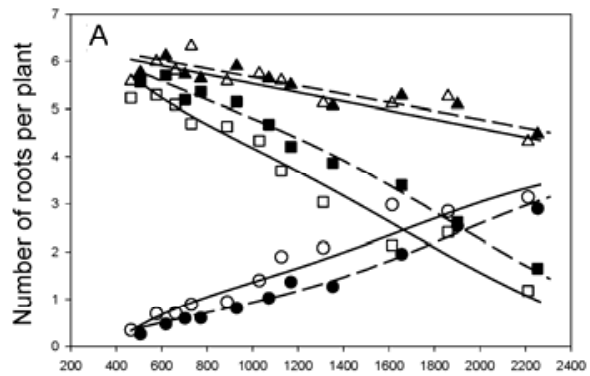

ii) Adventitious roots

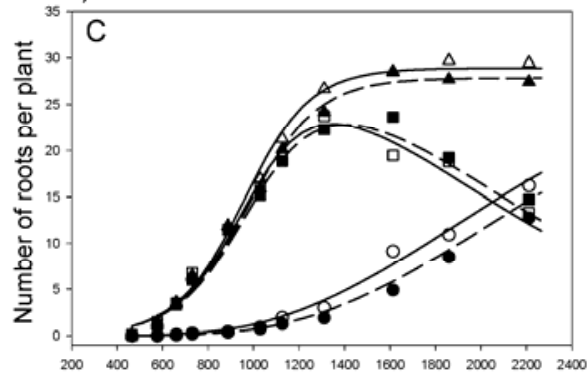

$1999 / 2000$

i) Seminal roots

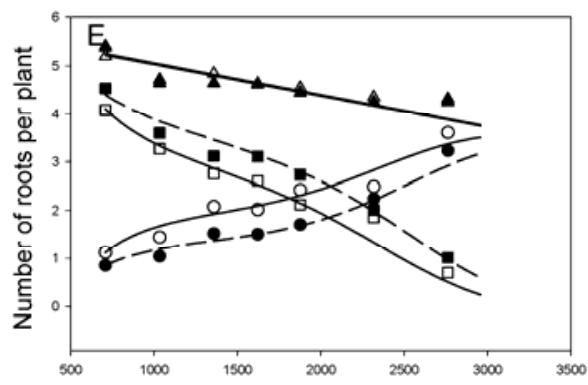

ii) Adventitious roots

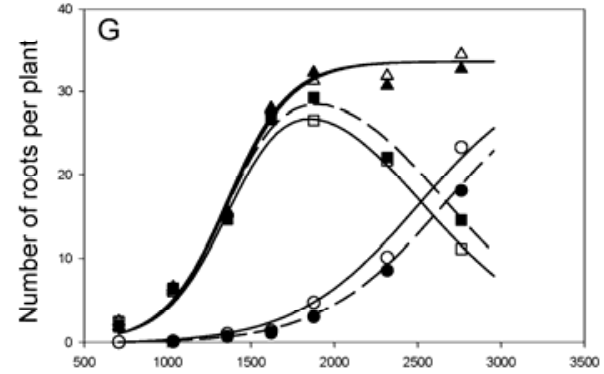

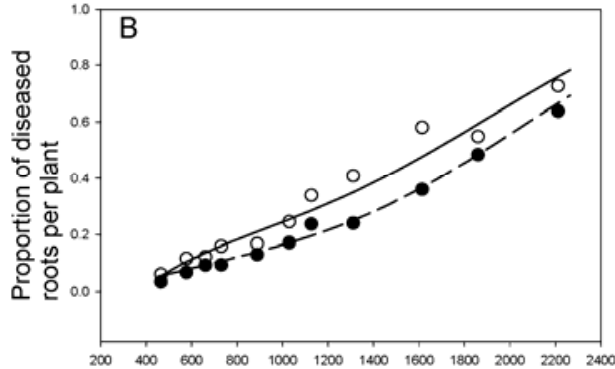
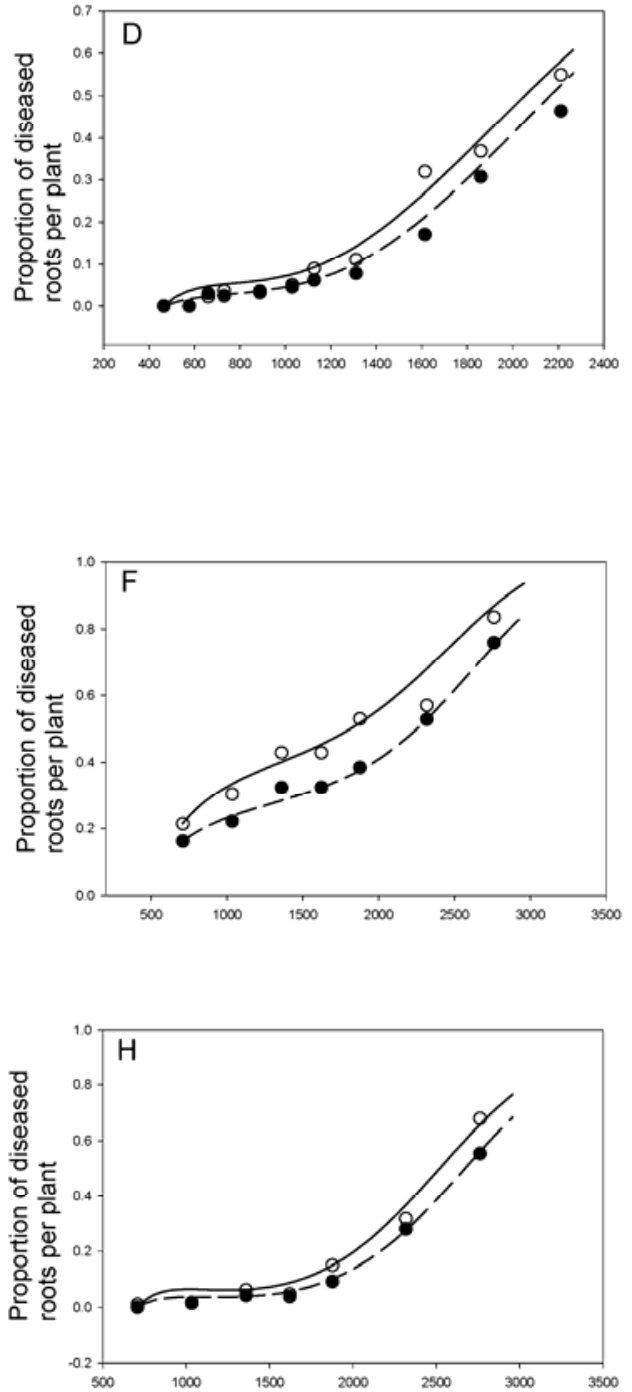

Time (degree days $>4^{\circ} \mathrm{C}$ )

Fig. 2. A, Change in number of diseased (circles), susceptible (squares), and total (triangles) seminal roots over time for untreated (open symbols) or treated (closed symbols) wheat plants for season 1998-99. B, Change in the proportion of diseased seminal roots over time for untreated (open circles) and treated (closed circles) wheat plants for season 1998-99. C, Change in number of diseased (circles), susceptible (squares), and total (triangles) adventitious roots over time for untreated (open symbols) or treated (closed symbols) wheat plants for season 1998-99. D, Change in the proportion of diseased adventitious roots over time for untreated (open circles) and treated (closed circles) wheat plants for season 1998-99. E, Change in number of diseased (circles), susceptible (squares), and total (triangles) seminal roots over time for untreated (open symbols) or treated (closed symbols) wheat plants for season 1999-2000. F, Change in the proportion of diseased seminal roots over time for untreated (open circles) and treated (closed circles) wheat plants for season 1999-2000. G, Change in number of diseased (circles), susceptible (squares), and total (triangles) adventitious roots over time for untreated (open symbols) or treated (closed symbols) wheat plants for season 1999-2000. H, Change in the proportion of diseased adventitious roots over time for untreated (open circles) and treated (closed circles) wheat plants for season 1999-2000. Model 2 was used to describe root growth and disease dynamics for untreated (solid lines) and crops treated (broken lines) with silthiofam. 
demic but not secondary infection thereafter. That the control afforded by the use of silthiofam is most evident following secondary infection is most likely a consequence of the nonlinear nature of the epidemic. Disease control during the early phase of an epidemic can be amplified by the multiplicative nature of secondary infection to generate large differences in final disease levels (11). Conversely, this means that differences in disease levels observed at the end of an epidemic may be the consequence of disease control acting much earlier in the epidemic.

Given that silthiofam was applied as a seed treatment, it is perhaps plausible to expect not only a reduction in the infectivity of soil inoculum but also a reduction in the infectivity of diseased seminal roots as a source of secondary inoculum and their capacity to spread disease. Hence, we extended model 1 and included separate but linked terms for the disease dynamics of seminal and adventitious roots with separate rates for secondary transmission of disease from diseased seminal and adventitious roots. Based on the disease progress curves, there clearly was a reduction in disease on the seminal roots that lasted for the duration of the epidemic, and on the adventitious roots during the second half of the epidemic. Once again, a reduction in the rate of primary infection of seminal roots was detected. However, no effect of seed treatment on rates of secondary infection from either seminal or adventitious roots was found.

We conclude that control of disease afforded by the seed treatment was restricted to reduced infection of the seminal roots by particulate soil inoculum and that, once infected, it did not affect the ability of these roots or of the adventitious roots to pass on the disease. The differences detected during the later stages of epidemics were the consequence of these initial effects on primary infection, subsequently amplified by secondary infection.

In these experiments, silthiofam reduced the number of diseased roots by $\approx 50 \%$ following primary infection. Yet, following secondary infection, the level of disease control declined to $\approx 25 \%$. If these trends had continued and the epidemic had been left to run its course, the level of disease control would have deteriorated further. Therefore, it follows that the rate of secondary infection is a principal factor determining final levels of disease control afforded by silthiofam. Model simulations, using parameters based around those obtained from fitting to field data, show how the percent reduction in diseased roots due to silthiofam declines with increasing rates of secondary infection. In the United Kingdom, the extent of secondary infection in winter wheat crops is most likely determined by soil conditions in the spring and summer months, with higher temperatures and water potentials generally stimulating the spread of disease (10). We postulate that the transient effect of silthiofam on the spread of disease combined with different levels of secondary infection determined by seasonal environmental differences will lead to

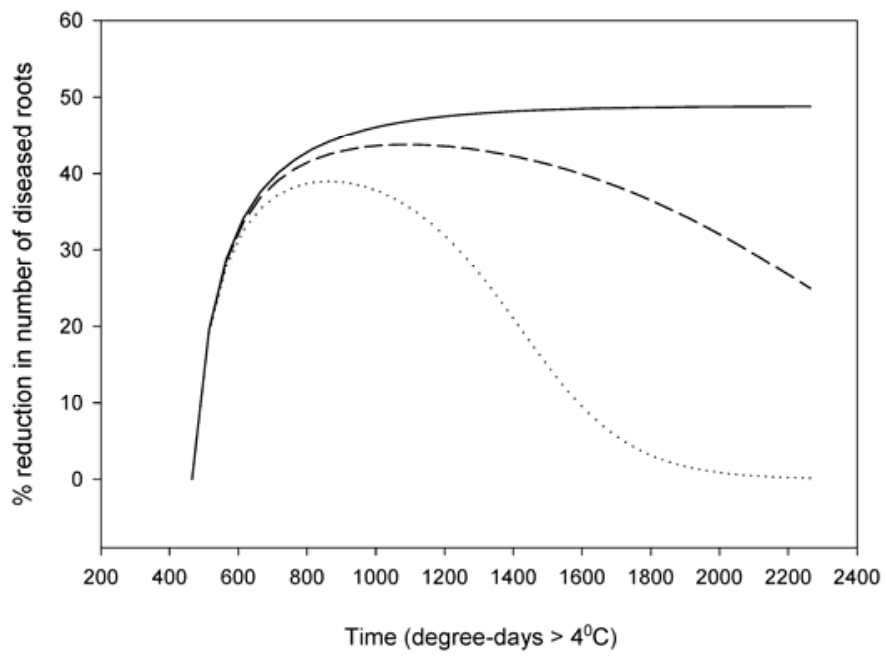

Fig. 3. Percent reduction in the number of take-all diseased roots with time (degree-days $>4^{\circ} \mathrm{C}$ ) for wheat treated with silthiofam for epidemics with no secondary infection (solid line), moderate secondary infection (dashed line), and severe secondary infection (dotted line). Values were obtained from the difference of two simulated disease progress curves for each level of secondary infection with parameter values $r_{p}=0.0007$ (no control) and $r_{p}=0.0003$ (control of primary infection by silthiofam). Rates for $r_{s}$ were $0,0.00007$, and 0.0002 for no, moderate, and severe secondary infection, respectively.

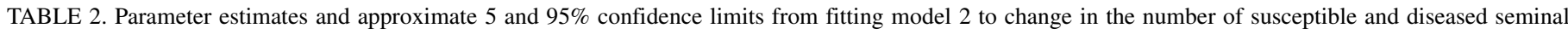
and adventitious wheat roots over time (degree-days $>4^{\circ} \mathrm{C}$ ) for wheat crops grown from seed either untreated or treated with silthiofam ${ }^{\mathrm{a}}$

\begin{tabular}{|c|c|c|c|c|c|c|}
\hline \multirow[b]{2}{*}{ Parameter $^{\mathrm{b}}$} & \multicolumn{3}{|c|}{ Untreated } & \multicolumn{3}{|c|}{ Treated } \\
\hline & Mean & $5 \%$ & $95 \%$ & Mean & $5 \%$ & $95 \%$ \\
\hline \multicolumn{7}{|l|}{ 1998-99 } \\
\hline$r_{d}\left(\times 10^{-3}\right)$ & 3.32 (fixed) & $\ldots$ & $\ldots$ & 3.32 (fixed) & $\ldots$ & $\ldots$ \\
\hline$b_{\text {sem }}\left(\times 10^{-4}\right)$ & -9.36 & -6.61 & -13.2 & -8.84 & -3.61 & -21.6 \\
\hline$b_{\mathrm{adv}}\left(\times 10^{-4}\right)$ & 2.35 & 2.14 & 2.58 & 2.31 & 2.21 & 2.43 \\
\hline$k_{\mathrm{adv}}$ & 28.9 & 27.3 & 30.6 & 27.8 & 27.2 & 28.5 \\
\hline$r_{p}\left(\times 10^{-4}\right)$ & 4.61 & 2.61 & 8.15 & 1.42 & 0.48 & 4.27 \\
\hline$r_{s 1}\left(\times 10^{-5}\right)$ & 17.6 & 8.79 & 35.1 & 22.1 & 15.8 & 31.0 \\
\hline \multirow[t]{3}{*}{$r_{s 2}\left(\times 10^{-5}\right)$} & 3.51 & 1.07 & 11.6 & 3.16 & 1.67 & 5.97 \\
\hline & $\mathrm{rss}^{\mathrm{c}}=15.28$ & $\ldots$ & $\ldots$ & $\mathrm{rss}^{\mathrm{c}}=6.74$ & $\ldots$ & $\ldots$ \\
\hline & $\mathrm{df}=38$ & $\ldots$ & $\ldots$ & $\mathrm{df}=36$ & $\ldots$ & $\ldots$ \\
\hline \multicolumn{7}{|l|}{ 1999-2000 } \\
\hline$r_{d}\left(\times 10^{-3}\right)$ & 3.32 & $\ldots$ & $\ldots$ & 3.32 & $\ldots$ & $\ldots$ \\
\hline$b_{\text {sem }}\left(\times 10^{-4}\right)$ & -6.60 & $\ldots$ & $\ldots$ & -6.60 & $\ldots$ & $\ldots$ \\
\hline$b_{\mathrm{adv}}\left(\times 10^{-4}\right)$ & 1.60 & $\ldots$ & $\ldots$ & 1.60 & $\ldots$ & $\ldots$ \\
\hline$k_{\mathrm{adv}}$ & 33.6 & $\ldots$ & $\ldots$ & 33.6 & $\ldots$ & $\ldots$ \\
\hline$r_{p}\left(\times 10^{-4}\right)$ & 6.50 & $\ldots$ & $\ldots$ & $\mathbf{3 . 5 0}$ & $\ldots$ & $\ldots$ \\
\hline$r_{s 1}\left(\times 10^{-5}\right)$ & 3.50 & $\ldots$ & $\ldots$ & 3.50 & $\ldots$ & $\ldots$ \\
\hline$r_{s 2}\left(\times 10^{-5}\right)$ & 7.50 & $\cdots$ & $\cdots$ & 7.50 & $\cdots$ & $\cdots$ \\
\hline \multicolumn{7}{|c|}{$\begin{array}{l}\text { Model } 2 \text { also was used to describe epidemics in 1999-2000. Disease dynamics were described for both epidemics using common values for all parameters except } \\
\text { the rate of primary infection, } r_{p} \text {. Values in bold indicate parameter that are significantly affected by the use of silthiofam. }\end{array}$} \\
\hline \multicolumn{7}{|c|}{$\begin{array}{l}\text { Parameters: } r_{d}=\text { rate of inoculum decay measured in }(\text { degree day })^{-1} \text {, dimensions }\left(\mathrm{T}^{-1}\right) ; b_{\text {sem }}=\text { rate of loss of seminal roots measured in roots }(\text { degree-day })^{-1} \text {, } \\
\text { dimensions }\left(\mathrm{L}^{-3}\right)\left(\mathrm{T}^{-1}\right) ; b_{\text {adv }}=\text { rate for production of adventitious roots measured in }(\text { degree-day })^{-1} \text {, dimensions }\left(\mathrm{L}^{-3}\right) ; k_{\text {adv }}=\text { maximum number of adventitious } \\
\text { roots measured in roots, dimensions }\left(\mathrm{L}^{-3}\right) ; r_{p}=\text { rate of primary infection measured in }(\text { degree-day })^{-1}(\text { inoculum unit })^{-1}, \text { dimensions }\left(\mathrm{T}^{-1}\right)\left(\mathrm{L}^{-3}\right) ; r_{s 1}=\text { rate of } \\
\text { secondary infection on seminal roots measured in }(\text { degree-day })^{-1}(\text { root })^{-1} \text {, dimensions }\left(\mathrm{T}^{-1}\right)\left(\mathrm{L}^{-3}\right) ; r_{s 2}=\text { rate of secondary infection on adventitious roots measured } \\
\text { in }(\text { degree-day })^{-1}(\text { root })^{-1} \text {, dimensions }\left(\mathrm{T}^{-1}\right)\left(\mathrm{L}^{-3}\right) \text {. Dimensions: inoculum and root densities are properly considered per unit area for a fixed soil depth in which } \\
\text { epidemiological significant infections occur. } \\
\text { rss = residual sums squared. }\end{array}$} \\
\hline
\end{tabular}


patchy disease control within fields and variable levels of disease control between crops.

In this study, we have shown how this type of analysis can be used to identify the epidemiological mechanisms of disease control. Moreover, we have been able to identify at what stage of the epidemic and from which form of inoculum, particulate soil inoculum, or diseased seminal or adventitious roots, the spread of disease is being controlled. This approach leads naturally to thinking about an epidemiological protocol for integrated management of take-all. Chemical, cultural (time of sowing, nitrogen source, and soil type), and biological forms of control, together with the interactions between them, can be similarly screened for their effect on primary and secondary infection, root growth, and inoculum decay. By using this form of modeling to assess the effects of various treatment combinations, we then can suggest strategies for optimizing their use (7). Moreover, by linking this form of model over consecutive seasons with simple parameters for the dynamics of inoculum between crops $(2,7,8)$, we can provide epidemiological explanations and predictions for the longterm effects of treatment on the invasion, persistence, and decline of take-all in continuous wheat crops.

\section{ACKNOWLEDGMENTS}

This work was funded by the Biotechnology and Biological Sciences Research Council, the UK Home-Grown Cereals Authority, and Monsanto Europe SA.

\section{LITERATURE CITED}

1. Bailey, D. J., and Gilligan, C. A. 1999. Dynamics of primary and secondary infection in take-all epidemics. Phytopathology 89:84-91.
2. Bailey, D. J., Kleczkowski, A., and Gilligan, C. A. 2004. Epidemiological dynamics and the efficiency of biological control of soil-borne disease during consecutive epidemics in a controlled environment. New Phytol. 161:569-575.

3. Beale, R. E., Phillion, D. P., Headrick, J. M., O'Reilly, P., and Cox, J. 1998. MON65500: A unique fungicide for the control of take-all in wheat. Proc. 1998 BCPC Conf. Pests Dis. 2:343-350.

4. Colbach, N., Lucas, P., and Meynard, J. M. 1997. Influence of crop management on take-all development and disease cycles on winter wheat. Phytopathology 87:26-32.

5. Foulkes, M. J., Scott, R. K., and Sylvester-Bradley, R. 2001. The ability of wheat cultivars to withstand drought in UK conditions: Resource capture. J. Agric. Sci. 137:1-16.

6. Gilligan, C. A. 1990. Comparison of disease progress curves. New Phytol. 115:223-242.

7. Gilligan, C. A. 2002. An epidemiological framework for disease management. Adv. Bot. Res. 38:1-64.

8. Gubbins, S., and Gilligan, C. A. 1997. Biological control in a disturbed environment. Philos. Trans. R. Soc. Lond. Ser. B 352:1935-1949.

9. Hornby, D. 1981. Inoculum. Pages 271-294 in: Biology and Control of Take-All. M. J. C. Asher and P. Shipton, eds. Academic Press, New York.

10. Hornby, D. 1998. Pages 58-62 in: Take-all Disease of Cereals: A Regional Perspective. D. Hornby, ed. CAB International, Wallingford, Oxon, UK.

11. Kleczkowski, A., Bailey, D. J., and Gilligan, C. A. 1996. Dynamically generated variability in plant-pathogen systems with biological control. Proc. R. Soc. Lond. Ser. B 263:777-783.

12. Pillinger, C. 2002. Effects of take-all (Gaeumannomyces graminis var. tritici) on below-ground resource capture and above-ground growth of winter wheat. Ph.D. thesis. University of Nottingham, UK.

13. Sallans, B. J. 1942. The importance of various roots to the wheat plant. Sci. Agric. 23:17-26.

14. Schoeny, A., and Lucas, P. 1999. Modeling of take-all epidemics to evaluate the efficacy of a new seed-treatment fungicide on wheat. Phytopathology 89:954-961.

15. Weller, D. M. 1988. Biological control of soil-borne pathogens in the rhizosphere with bacteria. Annu. Rev. Phytopathol. 26:379-407. 